\title{
NICKEL RECOVERY FROM RESIDUE OF HEAVY OIL USING NITRIC ACID.
}

\author{
Khalid M. Mousa ${ }^{\text {, Fouad A. A. Al-saady }{ }^{2} \text { and May E. Mahmood }}$ \\ 1 Chemical Eng. Dept, College of Eng. Nahrain University \\ 2 College of Pharmacy Kufa Univesity
}

\begin{abstract}
$\underline{\text { Abstract }}$
The fly ash of the residue of fired power station contains percentage of some valuable material. Their recovery is important regarding the environmental limitations and economically .The process of nickel recovery from ash using nitric acid was conducted. The effect of temperature ,acid concentration and time was studied and the limiting step was found .
\end{abstract}

Key:- nickel ,leaching, ash

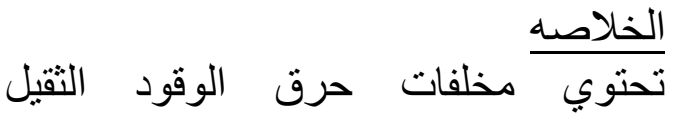
المستخدم في محطات انتاج الطاقة الكهربائية على كميات ليست قليلة من فئل المواد الثثينة وان استرجاعها يعتبر ذات اهية كبيرة من الناحية الاقتصادية ومن الناحية البيئية وذللك لاسعارها الغالية وللمددات البيئية. يتضمن هذا البحث نتائج

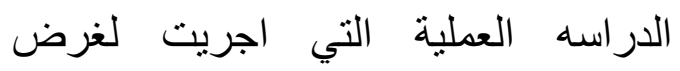
استخلاص النيكل من مخلفات حرق الوقود

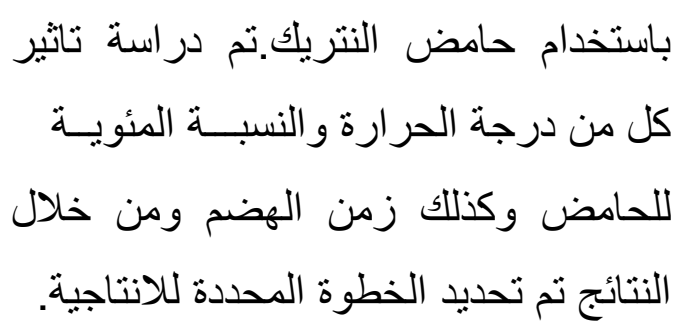

\section{Introduction}

There are many electric power stations that use a residue of distillation column as fuel which contains a considerable amount of metals such as vanadium, nickel, iron...etc .The recovery of such metals is very attractive due to limitation in environmental pollution and economic importance of these metals. The consumption of nickel is greatly increased due to its use in special steel alloy. The main resistance to leaching process are ,kinetics of the process ,intra-particle mass 
transfer and mass transfer from particle surface to surrounding media Jose(2000).

many researchers studied the recovery of nickel from ash of fired power station, Youngs et al.(1993); Chmielewski et al.(1997) considered that acid leaching is inefficient for nickel; Stas et al. (2006 ) studied the recovery of vanadium, nickel and molybdenum from fly ashes produced from heavy oil-fired electrical power station using two stage leaching process which consisted of an alkaline leaching to dissolve vanadium and molybdenum followed by sulfuric acid leaching to recover nickel .Ashraf( 2000 )used a leaching process to extract the nickel from Egyptian boiler ash ,the ash was directly leached with sulfuric acid under atmospheric pressure and in an autoclave. Shang et al.(1998) established an extraction flow sheet in which fly ash was leached in a solution containing ammonium sulfate to recover nickel. Ottartun(1977) used $\mathrm{H}_{2} \mathrm{SO}_{4}$ coming from the solvent unit extraction to leach the ash. During leaching, vanadium is kept in its tetravalent state by feeding $\mathrm{SO}_{2}$ to the solution. Solvent extraction of $\left(\mathrm{V}^{+4}\right)$ is performed with $20 \%$ di(2-ethylhexyl) phosphoric acid and $15 \%$ tributylphosphate. The raffinate is returned to the leaching stage. J. Marcantonio(2010) studied the removal of molybdenum, vanadium and nickel from unsupported spent catalysis. A corrosion problems arises in using sulfuric acid(used by previous researchers ).The main objective is to find the optimum conditions of Nickel recovery from fly ash using the nitric acid as a leacher (its less corrosive than sulfuric acid)and to develope economical and environmentally acceptable process . 


\section{Experimental Work}

$F_{\text {ly ashes were collected from }}$

Al-Dura Electrical power station (Baghdad) .Leaching agent used was Nitric acid supplied by (Fluka) ,Ether supplied by (BDH).

Mineral composition of the solutions obtained by digestion of the fly ashes was determined by atomic absorption spectrometer (Shimadzu) . A mass of ashes was grinded by ball mill, sieved in order to obtained $(<63 \mu \mathrm{m})$, washed by water to remove any soluble agent, dried to $105{ }^{\circ} \mathrm{C}$, washed by ether (to remove undesirable accumulated organic residual that may prevent the leaching process) ,dried and mixed to render the solid homogeneous. Solutions of nitric acid were prepared with different percentages $(10 \%, 20 \%$ and $30 \%$ ), then $5 \mathrm{mg}$ of the residuals flay ash samples was used for each experiment, mixed with $10 \mathrm{~cm}^{3}$ with the solution of $\mathrm{HNO}_{3}$ in $25 \mathrm{~cm}^{3}$ Pyrex test tube and shacked in desired temperature $\left(30,40,50\right.$ and $\left.60{ }^{\circ} \mathrm{C}\right)$ in AAKE thermo stated water bath at different contact times. Samples were settled using a centrifuge .The solution was then taken to analyses using atomic absorption spectrometer. 


\section{Ressults S \& Disscusion}

The effect of temperature

and time for different nitric acid concentration is shown in figures 1, 2 and 3. Examining these figures indicates that the recovery of nickel increased with increasing time and temperature. A sharp increase in nickel recovery was noted at the first half hour,then a more sluggish curve was obtained, this was attribute to a decline in driving force due to the consumption of the of most nickel in solid particles .On the other hand it was found that a small increase in temperature leads to high shift in the recovery of nickel, this can be explained as fallow, there are three main resistances or steps controlling the leaching process ,kinetic of the process, intra particle mass transfer and mass transfer from particle to the surrounding media. If the controlling step is the intraparticle, then the effect of temperature came from its effect on effective diffusivity. If the chemical reaction step is the controlling step then the temperature due to effects the constant of reaction rate, Jose et al (2000). The chemical step is usually much more temperature sensitive than the physical steps so the kinetic in this system is mostly the controlling step. 


\section{Journal of Petroleum Research \& Studies}

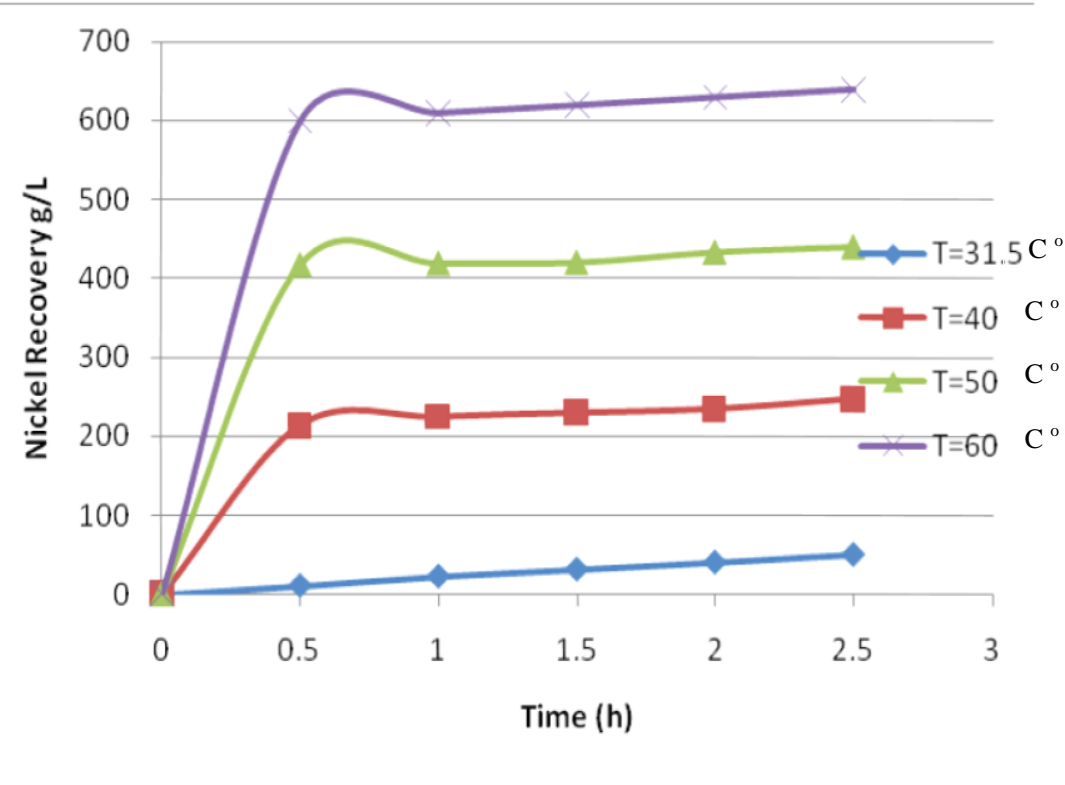

Fig (1) : Effect of time and temperature on nickel recovery using $10 \%$

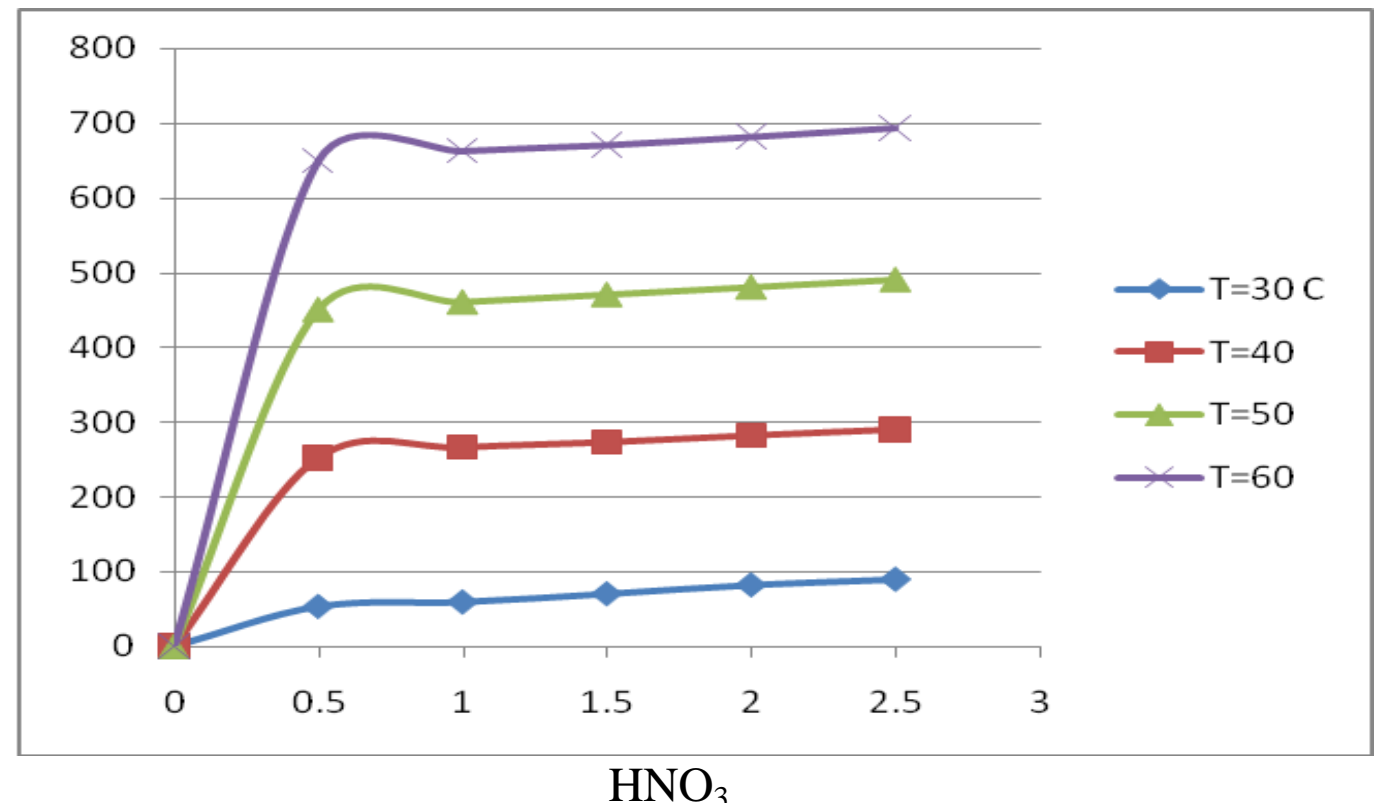

Fig (2): Effect of time and temperature on nickel recovery at $20 \% \mathrm{HNO}_{3}$ 


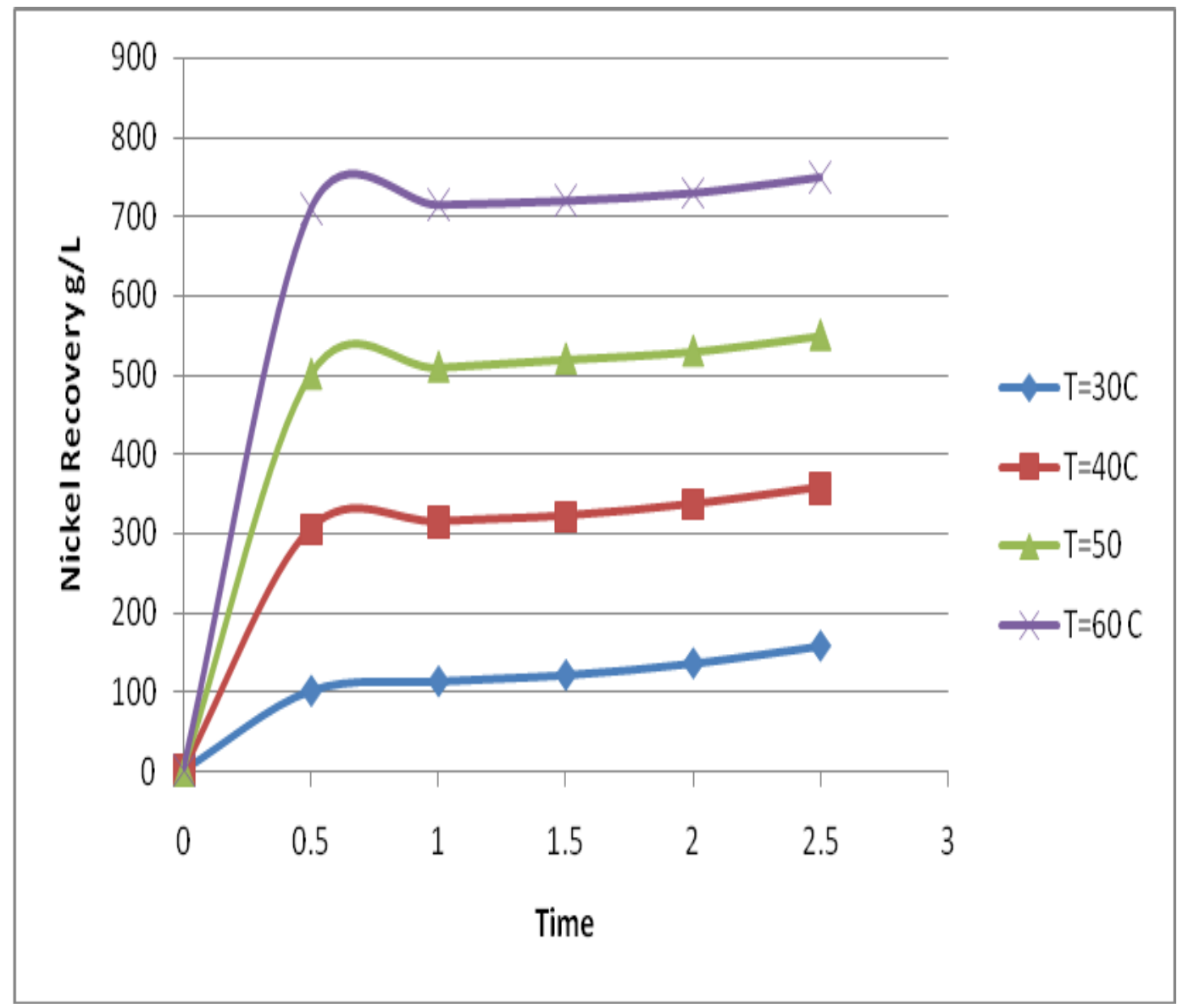

Fig (3) : Effect of time and temperature on nickel recovery using 30\% $\mathrm{HNO}_{3}$

The effect of $\mathrm{HNO}_{3}$ percentage is shifts the recovery percentage on nickel recovery to high values for $10 \% \mathrm{HNO}_{3}$, the was studied by varying the recovery of nickel is $68.5 \%$ while concentration of $\mathrm{HNO}_{3}$ at increasing $\mathrm{HNO}_{3}$ to $30 \%$ and constant temperature at $60{ }^{0} \mathrm{C} \quad$ keeping the other conditions and the results is shown in figure constant lead to $80.3 \%$ recovery 4 .It is clear from this figure that of nickel) increasing the 


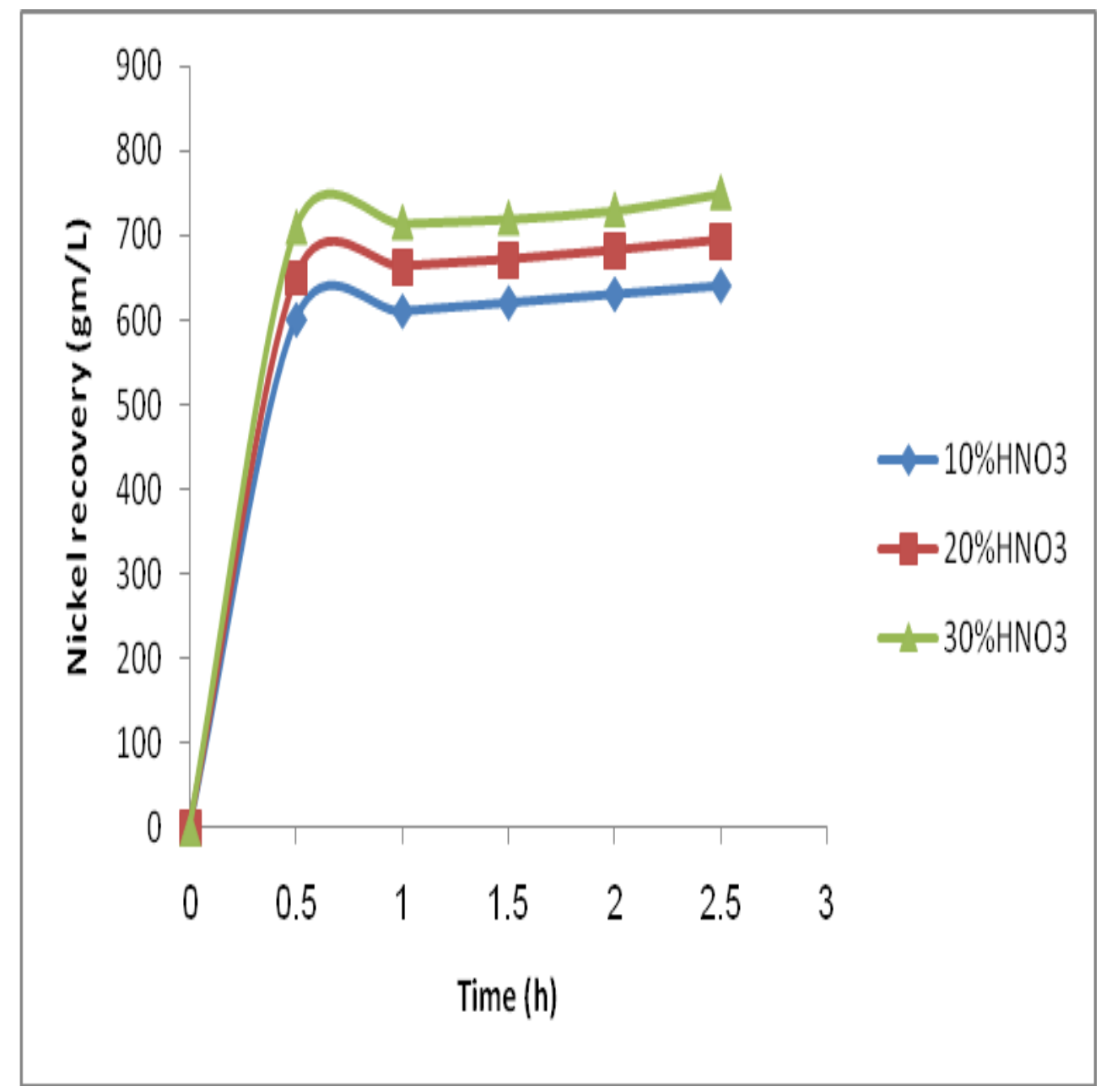

Fig (4) : Effect of time and $\mathrm{HNO}_{3}$ percentage on nickel recovery at $60{ }^{\circ} \mathrm{C}$ and leaching time $=1 \mathrm{~h}$.

Figure 5 shows a comparison with the results of Amer (2000) in which $60 \mathrm{~g} / \mathrm{L}$ sulfuric acid and $70-90{ }^{0} \mathrm{C}$ where used, it was found that the nickel recovery increased with increasing temperature( $60 \%$ of nickel was recovered after one hour and 70 ${ }^{0} \mathrm{C}$ ) while in this work $80.3 \%$ of nickel was recovered when using $60^{\circ} \mathrm{C}$ and in hour.

The leaching via $\mathrm{HNO}_{3}$ is preferred due to easy handling and less cost of material construction due to serious problems of corrosively of $\mathrm{H}_{2} \mathrm{SO}_{4}$. On the other hand a high recovery percent was obtained in using $\mathrm{HNO}_{3}$. 


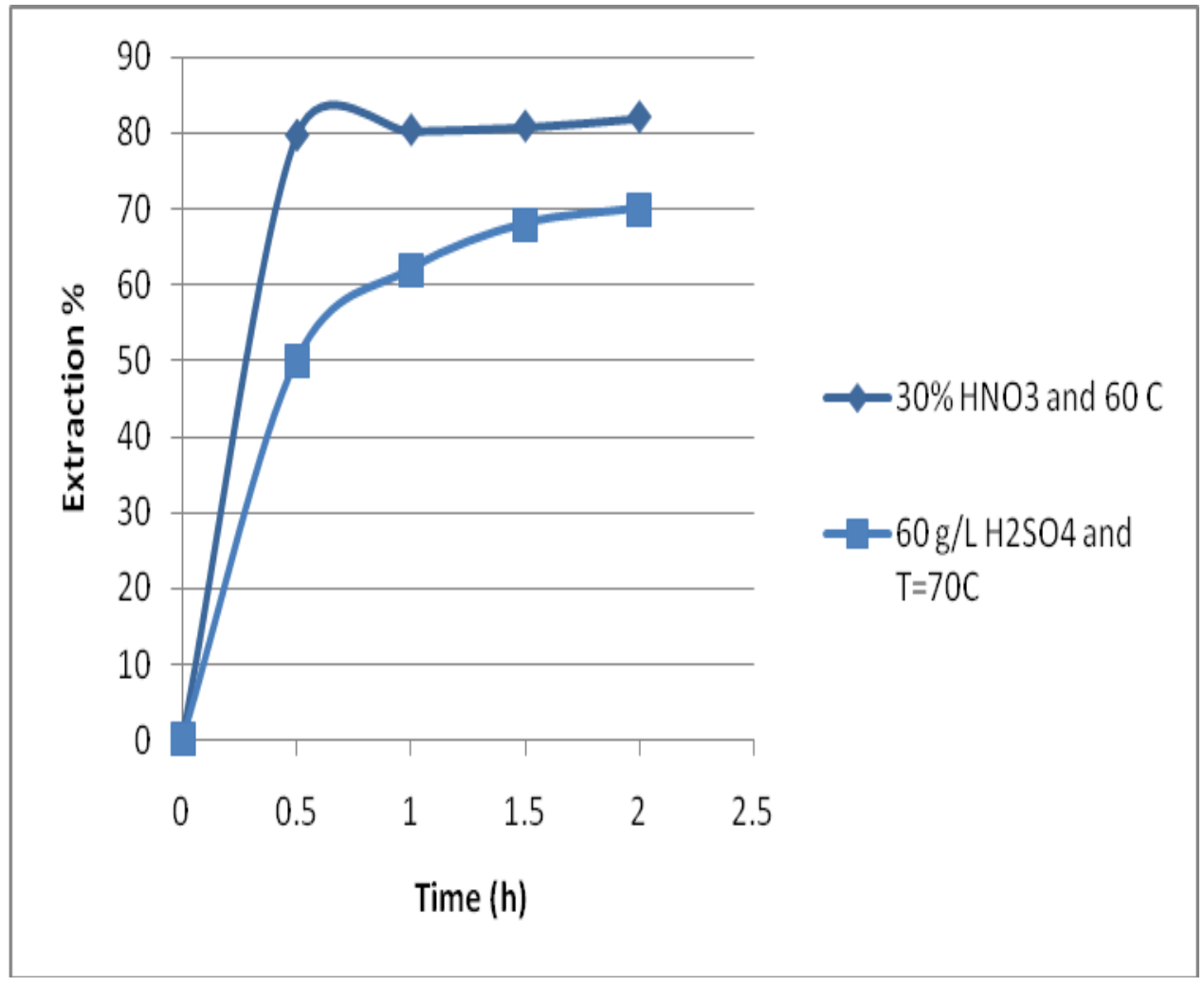

Fig (5) : Comparison with the results of Amer

\section{Conclusion}

\section{The Extraction of nickel}

from the ash of oil fired power station was achieved using $10 \%, 20 \%$ and $30 \%$ nitric acid .

About $80 \%$ of nickel was recovered at $30 \%$ nitric acid and $600 \mathrm{C}$.The rates of extraction increase with the increase in nitric acid concentration and temperature and most of nickel was recovered at the first half of an hour.This study suggested that using nitric acid is applicable to recover the nickel from the ash of fired power station 


\section{Journal of Petroleum Research \& Studies}

\section{References}

1- Ashraf Amer,2000 "Processing of Egyptian Boiler-ash for Extraction of

Vanadium and Nickel " Physicochemical problems of Mineral Processing,

v34,pp153-161.

2- Chmielewski AG, Urbanski TS, Migdal W, 1997, "Separation technologies for metals recovery from industrial wastes”, Hydrometallurgy 45 ,pp $333-$ 344.

3- Jose Luis,ium Cury,Newton Libanio "Vanadium Recovery by Leaching in Spent Catalysts for Sulfuric Acid Production",revista decieci \&tecnologia ,V8 .NO16.PP85-90

4- Ottartoun H, Strandell E,1977” Solvent Extraction of Vanadium (IV) with Di-(2-ethyl-hexyl) phosphoric Acid and Tributylphosphate", ISEC , pp. $501-508$.

5- Paul J. Marcantonio ,"Process for Metals Recovery from Spent Catalyst", US patient N.7736607 B2 ,Jun. 15

6- Shang-Lin Tsai,Min-Shing Tsai1998 "A study of the Extraction of Vanadium and Nickel in Oil-Fired Fly Ash",Resources ,Conservation and ecycling, 22,,163-176.

7- Stas Jamal, Ajaj Dahdouh , Omar Al-chayah, 2006"Recovery of Vanadium, Nickel and Molybdenum from fly ash of heavy oil-fired electrical power station”, Chemical Engineering, V 8 ,PP67-70 . 
8- Youngs W D, Rutzke M, Gutenmann WH, Lisk DJ,1993,” Nickel and

vanadium in foliage in the vicinity of oil fired power plant",

Chemosphere V. 27 , NO. 7, 1269-1272 